\title{
Using Dewey's Conception of Democracy to Problematize the Notion of Disability in Public Education
}

Ricky Dale Mullins*

Eastern Kentucky University

*Corresponding Author: ricky.mullins@eku.edu

Received : 2018-12-10

Accepted : 2019-04-29

How to cite this paper: Mullins, R.D., (2019). Using Dewey's Conception of Democracy to Problematize the Notion of Disability in Public Education, Journal of Culture and Values in Education, Volume 2 (1), 1-17.

\begin{abstract}
In this paper I examine ways in which students with disabilities have the capacity to be full, contributing citizens within a participatory, communicative, and pluralistic democracy. In many instances, institutions such as schools provide barriers that disallow and dissuade students with disabilities from full participation in society and their education, which prevents them from becoming co-creators of their educational experience. I argue that in a Deweyan democracy, all students must have not just the right, but be allowed to grow in their capacity to develop into fully participating, contributing citizens. My hope is that by situating disability and special education within Deweyan democratic discourse it will be possible to render that discourse more genuinely inclusive of all students, so that the needs of all are met and the unique contributions of each become a part of the educational process.
\end{abstract}

Keywords: Democratic Education, Citizenship, Special Education, Civic Education, Social Foundations

\section{Introduction}

"The democratic faith in human equality is belief that every human being, independent of the quantity or range of his personal endowment, has the right to equal opportunity with every other person for development of whatever gifts he has" (LW 14:226-227).

"The belief in the capacity of our people, then, requires a continual affirmation, and a sensitivity to the ways it can be diminished" (Rose, 2004, p. 214).

As acknowledged and explicated in the call for proposals for this special issue of The Journal of Culture and Values in Education, the American educational system often restrains and limits the intellectual growth of students, despite the fact that embedded in American education is the rhetoric of inclusion. As educational researchers, we like to talk about inclusion, but we do not actually know how to do it. Therefore, the implementation of inclusion has been sharply 
criticized in the literature. For example, Baglieri, Bejoian, Broderick, Connor, and Valle (2011) note:

Imagining schools as places where children can find belonging and community conjures values and ideas with which few would argue. Democracy is posed as the political ideal of our culture. Even federal education policy asks us to leave no child behind. How is it, then, that an idea and a value that upholds social equity-embodied within the now-familiar educational term inclusion-ends up as the source of contention in a polarizing debate now spanning decades? (p. 2123)

Arguably, the word inclusion itself is most typically associated with special education. Although a major focus in special education is tailoring instruction to support the needs of students with disabilities (SWDs) in the form of an Individualized Education Plan (IEP), this document often limits, constrains, and silences the uniqueness of the student (Martin, Van Dyke, Christensen, Greene, Gardner, \& Lovett 2006), although it was intended to be a solution to the problems faced by SWDs. Nespor and Hicks (2010) further note:

The IEP is a peculiar technology of 'performativity' (Ball 2006) in that it can be used both as an instrument of control by schools - defining the limits of what they are obligated to do, specifying how the child is to be made visible, and accountability in institutional terms - and, less frequently, by parents, who can use it to specify what the school should provide their child and make the teacher and school accountable in terms of specific goals. (p. 316)

To prevent IEPs from continuing to serve as a means of control, we need to break away from "pedagogies of the same" (Lingard, 2008, p. 248), and start recognizing all students present unique instructional needs and contributions to the classroom and society.

Offering a way to make such a break, John Dewey's concept of democratic education provides a realistic, even necessary path to the intellectual liberation of all students, and in particular, SWDs. I came to understand the necessity of a Deweyan lens as a social studies educator, special educator, and administrator. In this paper, I draw on that experience and use SWDs as a focal point to show what it would look like if we reconceptualized citizenship to extend beyond what is commonly associated with civic engagement, voting for instance. I therefore begin with a discussion of Dewey's pluralistic, participatory, and communicative democracy. Next, I examine citizenship in American society and Deweyan democracy. I conclude by arguing that by using Deweyan democracy as a guide for supporting the needs of SWDs, schools can reimagine education to help SWDs develop their potential to become fully participating citizens and leaders.

\section{The Current Status of Disability: Two Diverging Models}

Extensive involvement by the United States Federal Government in the education of individuals with disabilities began with the adoption of the Education for All Handicapped Children Act (EHA, 1975). In 1990 Congress reauthorized EHA, renaming it the Individuals with Disabilities Education Act (IDEA, 2004). Since that time, the rights of students with disabilities has "had to 
be reinterpreted time and time again" (Bérubé, 2003, p. 55). Under the current authorization in 2004, IDEA has 14 categories of disability including: autism, deaf-blindness, deafness, developmental, emotional disturbance, hearing impairment, intellectual disability delay, multiple disabilities, orthopedic impairment, other health impairment, specific learning disability, speech or language impairment, traumatic brain injury, and visual impairment, including blindness. A student is considered to have a disability if he or she meets the federal guidelines and criteria and is eligible for special education services when this identified disability adversely affects his or her educational performance (Center for Parent Information and Resources, 2017).

IDEA guarantees certain rights for individuals with disabilities. Within public education, these rights are generally granted and guaranteed when a student is eligible to receive special education services (Ben-Porath, 2012). Nevertheless, there is scholarship that is critical of the very nature and underpinnings of special education. For example, Gabel and Connor (2008) argue that, "many critical scholars question the very foundation of the field of special education" (p. 377). This is because some scholars believe that "Once captured by the special education industry, the individual becomes an unending object of study for a well-intentioned cadre of professionals" (Baglieri et al., 2011, p. 2133), meaning that the child who is now part of the special education system will forever have decisions made for them by the experts who decided they belonged in the system in the first place. The system of special education has often been seen as an overall failure and giving it a nominal distinction as a separate field, professionalizes and legitimatizes the concept of special education (Baglieri et al., 2011). While these issues are of importance and merit further scholarship, resolving this ongoing controversy is beyond the scope of this paper. Here, the goal is to expand avenues and possibilities of Deweyan democracy while operating within this unsettled, ever shifting configuration of public education. In pursuit of such an expansion of democratic possibilities, it is useful to reflect on the dominant models of disability.

Currently there are two dominant models used to examine disability: The medical model of disability and the social model of disability. My own approach more closely aligns with the latter. Advocates of the medical model approach disability as if it were a disease that needs treated, the ideal outcome being an individual achieves "normality" (Shyman, 2016, p. 367), depending on what normal means in the context of their culture. Within public education, the medical model is more prevalent, especially within special education. Therefore, a student's performance is assessed by a series of observations and checklists that add up to pathological societal assessments, these prevalent in addressing issues of disability in public education (Garrison, 2010). Moreover, in public education, once a student has been identified as having a disability and is deemed eligible to receive special education services, the goal then is to help the child "catch up" to their peers. Therefore, the impression is given that having a disability is a condition that prevents one from achieving at an ideal level.

In contrast, advocates of the social model posit that disability is a societal construct (Danforth, 2008), which could vary depending on the cultural context. That is not to say biological factors such as dysfunctional limbs do not affect the manner in which individuals can engage in certain activities, such as climbing stairs (Anastasiou \& Kauffman, 2013). Nevertheless, Lekan (2009) 
argues, "Justice requires that we repair the environments not the people" (p. 216). If individuals with disabilities have issues accessing physical structures, or struggle to have academic success, it is, according to social model advocates, the environments that need altering, not the individuals. My paper suggests altering the social and political environments to be more pluralistic, participatory, and communicative, which aligns directly with the concept of Deweyan democracy, which I will explicate in more detail later on in this paper. Such a Deweyan approach confronts and rejects the medical model. For instance, O'Brien (2016) notes:

[I]nstead of focusing on what children cannot do, educators would view all children as strong, capable, and competent. And "disability" would be thought of as an addition to the concept of diversity, that is, a difference in degree, not type. (p. 481)

Examining disability from this non-pathological perspective problematizes the notion of how the citizenship of individuals with disabilities is approached in an institutional setting because "inclusive education is about the participation of all children and young people and the removal of all form of exclusionary practices" (Barton, 1998, p. 84-85).

\section{Dewey and Disability}

Examining Dewey sheds light on possible ways to reconstruct the environments that currently prohibit and discourage individuals with disabilities from achieving that needed to participate in democratic citizenship. Although Dewey did not discuss disability directly, his theoretical underpinnings help to situate him within the discourse of disability, aligning him more closely with the social model. To Dewey, the focus of education should be "continuity of growth" and that looks different for every student and cannot be measured by a standardized assessment of any sort (Garrison, Neubert, \& Reich, 2016, p. 186). Given the uniqueness of each individual, there is no test that can provide a valid assessment of growth in every person. Besides, it is not up to a test to determine growth, but it is up to the teacher who must be able to identify "what experiences best promote growth" (Mason, 2016, p. 92). Additionally, growth can be observed and "is present wherever life exists" (Danforth, 2008, p. 58). For example, if one day a student is not able to do a given task and then later that student can complete it, simply put, that student has experienced growth.

Dewey had "discomfort with intelligence testing" because the results are used as evidentiary support to label or categorize someone as inferior or superior (Danforth, 2008, p. 50). Danforth (2008) indicates that these labels serve to stigmatize "while claiming scientific neutrality" ( $p$. 59). Additionally, "labeling directs the teacher's attention to conformity instead of the uniqueness of each person" (Furman, 2015, p. 62). In fact, no one has a cognitive disability until he or she takes an IQ test (Garrison, 2012). Dewey argues that inferiority and superiority can only be in relation to a task (Danforth, 2008). Thus, Dewey wrote:

There are many modes of superiority and inferiority as there are consequences to be attained and works to be accomplished. And until society becomes static new modes of activity are continually developing, each of which permits and exacts its own specific inferiorities and superiorities. There is doubtless some degree of correlation between traits which promote 
superiority in more than one direction. But the idea of abstract, universal superiority and inferiority is an absurdity. (MW 13:49)

Consider a student I taught, Justin. ${ }^{1}$ The intelligence test he was given indicated that he had an intellectual disability, suggesting that he was intellectually inferior when compared to his sameage peers. However, Justin knew how to do a variety of tasks valued in the social context of the vocational classroom such as, but not limited to, stacking lumber, sawing, hammering, and sweeping. His peers probably did not know how to do many of the aforementioned tasks. So, given a variety of tasks to complete in a woodshop, who then is inferior, Justin or his peers of putatively "normal" IQ's?

\section{Deweyan Democracy}

\section{Pluralistic Democracy}

Within a Deweyan democracy, perceptions of ability and disability labels begin to break down and lose meaning, which I will discuss momentarily. Within American society, the word democracy is often spoken, but rarely truly understood and applied in a Deweyan sense. Most American citizens are familiar with the term because they are familiar with the notion of American democracy. In fact, "we tend to think of democracy as something that exists somewhere else, typically in Washington, D.C., or the state capitol, and is supported by the voting of dutiful individuals" (Stitzlein, 2014, p. 66). Although democracy is related to government, it is as well and more so a way of life, a way of looking at the world. Democracy is something that emerges and, should it thrive, repeatedly reinvents itself to reflect the will of a democratic people. Thus, it is not a static entity to be preserved in a singular form. It is an intellectual space where experiences of citizens are blended to discover the best ideas for the transformation of reality so that the realities created best serve the aspirations of the people. When speaking of democracy, Dewey proposes two questions as standards for evaluating any society. The first (internal) standard is based in the question of "How numerous and varied are the interests which are consciously shared?" (MW 9:89). He asks this question as a way of assessing if a particular configuration is actually a democracy. This question is meant to address the issue of whether everyone's' interests are being represented and if there is a direct effort to ensure that the views of all are being shared among the members of the democracy and considered in the decision-making process. It urges the society to discover interests held in common that, when properly addressed, leads to decisions that serve well the whole of the people, the common good. The second (external) question that must be considered, according to Dewey, is "How full and free is the interplay with other forms of association?" (MW 9:89). This question concerns whether the group has free and open exchanges with other ways of life different from those currently found within the society. It urges openness to otherness and offers hospitality to strangers. Both standards point toward an inclusive pluralism.

Dewey examines his two standards by considering a non-pluralistic situation where interests are shared, but not varied or open to other forms of exchange. He asks us to consider a band

\footnotetext{
${ }^{1}$ Here and elsewhere in the paper, pseudonyms have been used to protect the student's or teachers' identity.
} 
of thieves. Thieves share a common interest in stealing. However, this common interest is limited, and the thieves do not have any open exchanges with those affected who are outside the group. Doing so, opening out to a broad public, would result in the demise of the organization as an organization. Although each group member may have a voice, the group lacks diversity of perspective, and as Dewey notes, "Hence, the education such a society gives is partial and distorted" (MW 9:89). However, if a group forms where community organizations, schools, for instance, in which a broad range of participants, in schools, for example, students, teachers, administrators, parents, and other stakeholders are involved in a dialogic relationship, then Deweyan democracy starts to form. In such organizations, the interests are shared and varied and the exchange between the external (community) and internal (school) is open and unrestrained. Ideally, every citizen in a democracy has a role and a contribution to make to help that democracy not just survive, but thrive. Dewey's two standards point toward a participatory, pluralistic democracy.

Garrison et al. (2016) argue that, "We can say that a plurality of interests shared within a community is a necessary precondition of education for democracy" (p. 98). For example, the standard of plurality within a community is realized when those within a group share common interests. This can be explained by examining educational decisions made within a school itself. When a school shares a common interest in helping students find their unique place in society, the school has the potential to provide democratic education. If this school is to provide effective democratic education, the faculty has to make a concerted effort to include the voices of outside members such as social services, disability advocates, local colleges, parents, and other stakeholders. Garrison et al. (2016) argue, "The key point here is that for the development of its democratic relations and experiences, a given group, community, or society needs generous and unhindered exchanges taking place with other groups, communities and societies," (p. 98), these are people with some common interests. In order to educate for democracy these external exchanges are of utmost necessity.

Therefore, it is sufficient to say that a school, when educating for democracy, must have an openness to the local, national, and global community. This relationship should benefit and edify both the school community and the community in which the school resides. For example, consider a program that one of my colleagues had in which SWDs operated a consignment shop on the school property. The students did everything in the store from working with and waiting on customers to taking donations. The public would donate, buy, and interact with the students on a daily basis. This relationship helped to upset a binary present in modern society, that is the distinction between manual and mental labor. The students solved problems and dealt with customer issues. Therefore, the public could gain insight into:

The mental processes that enable service. The aesthetics of physical labor. The complex interplay of the social and mechanical. The choreography of hand, eye, ear, brain. The everpresence of abstraction, planning and problem solving in everyday work. (Rose, 2004, p. $x \mathrm{x})$

This situation helped the public to not miss the interplay of mind and work because they could observe the SWDs engaging and thriving in this space. This dialogical relationship also allowed 
the students to become fully engaged with the local culture and community, and allowed for meaningful interaction between the students and the public.

\section{Democratic Participation}

In a Deweyan democracy, everyone has more than solely a right to participate; saying someone has a right to do something can mean very little. Dewey argues that everyone also has the capacity, or ability to participate in some way. When someone has a right to do something that simply means that his or her freedom is secured by law, such as the right to free speech in America. However, arguing that everyone has the capacity adds an extra element because then the argument moves beyond formal rights secured by law, towards critical consideration of the notion that no one is excluded based on perceived lack of capacity, which entails that everyone has the potential to participate as a contributing citizen. Therefore, if the capacity is lacking it must be developed and nurtured whenever possible.

Educating individual democratic capacity is essential to any vibrant democracy. It enables positive, active, substantive freedom. For example, Dewey posits that, "It is the aim of progressive education to take part in correcting unfair privilege and unfair deprivation, not to perpetuate them" (MW 9: 126). Education should seek to develop that which a person is capable of, which is unknown until a student is allowed to explore that capacity in various settings. Therefore, it is clear that Dewey was not in favor of anyone being excluded; instead, he supported the inclusion of all that are affected by a policy, decision, or law. However, the inclusion of all is only possible in educational environments that are democratic. Garrison et al. (2016) speak to the nature of democratic education when they say, "Education in a democratic sense has to prepare sufficient opportunities for individuals to realize their autonomy de facto in the complex contexts of modern power constellations" (p. 148). Therefore, the individual citizen must realize that he or she has autonomy within a genuinely pluralistic democracy and some students may miss this realization if they do not have the opportunity to participate.

In American democracy, as it presently exists, not everyone can participate, even in the restricted legal sense, sometimes because it is claimed of a person that he or she is intrinsically lacking in capacity. In fact, there are laws in certain states that prohibit and restrain individuals with disabilities from civic engagement such as voting. This is an example of individuals having a right, here, to vote, by virtue of their being American citizens of proper age, but that right is affected by laws set around evaluation of their capacity. For example, Disability Justice (2016) notes:

- 7 states deny the right to vote to: "idiots or insane persons"

- others deny the vote to those of "unsound mind, non compos mentis", or those who are not of "quiet and peaceable behavior"

- 16 states bar those adjudged mentally incompetent or incapacitated from voting

- 4 state constitutions bar people "under guardianship" from voting (Par. 5)

Therefore, when looking at the concept of right to participation, one should consider exactly what it means to be a democratic citizen. If participation is conferred by citizenship, and citizenship is defined by civic engagement through participation in activities such as voting, 
what then does exclusion for the reasons described in the laws mean for the citizenship and active civic participation of individuals with severe disabilities? If citizenship is reduced to the aforementioned elements, then people with disabilities are essentially not citizens in their own country or state. Nussbaum (2010) takes up the argument of participation and identifies three levels of impairment that are pertinent to this discussion, one that allows for a person to fully participate; one recognizes that a person may be able to make political decisions but needs the assistance of the guardian of some type to do so; and the last in which the person is completely dependent upon a guardian to speak on his or her behalf because a disability prevents the person from doing so on his or her own. Nussbaum (2010) argues that every person should have a vote. Nussbaum (2010) even goes so far as to say in the case of individuals with significant disabilities, "There is no good reason to refuse a surrogate arrangement in this area, and very strong reasons to accept it" (p. 93). Some could argue that this is dangerous because the person being represented may not have the capacity to reason through certain issues, and if a surrogate voted for them, they could misrepresent the person they are aiding. However, what is the difference between surrogates who may misrepresent someone's wishes and people who do not vote or does so while being uninformed? It seems when examining this situation closely, Nussbuam (2010) appears to be correct in that "there is no good reason to refuse a surrogate" (p. 93).

\section{Democratic Communication}

Full citizenship in democratic societies for individuals with disabilities is not possible unless communication is present, acknowledging that communication in this instance does not necessarily mean speaking. For example, Dewey notes, "communication insures participation" (MW 9:7). Without communication involving all members of the democracy, neither of Dewey's standards can be met, as there is not communication among all members both inside and outside of the group. As Dewey notes, "In order to have a large number of values in common, all members of the group must have an equable opportunity to receive and take from others. There must be a large variety of shared undertakings and experiences" (MW 9:90). Without full and free communication individuals cannot know if they have shared interests with others. Dewey argues that, "Lack of free and equitable intercourse which springs from a variety of shared interests makes intellectual stimulation unbalanced" (MW 9:90). Therefore, inclusive communication is a must to maintain the integrity of the democracy. Consideration of participation in the societal discourse of individuals with disabilities must be recognized as essential to the inclusion of such individuals in the democratic process and, for one to be included, he or she has to be able to explain to others, to the fullest extent possible, his or her needs, desires, and aspirations. Dewey is adamant about the centrality of communication in participatory democracy. He tells us that:

Society not only continues to exist by transmission, by communication, but it may fairly be said to exist in transmission, in communication. There is more than a verbal tie between the words common, community, and communication. Men live in a community in virtue of the things which they have in common; and communication is the way in which they come to possess things in common. (MW 9:7) 
For a society to persist, open communication must also persist. Communication in a community creates new shared interests, as well as revealing already existing interests. Thus, if individuals with disabilities are excluded from the conversation, they cannot know of others interests and conversely, others cannot know of their interests.

The notion of communication becomes problematic when thinking of individuals with severe disabilities, especially if such an individual cannot communicate in the usual sense by speaking or writing. This person can still be a contributing and participating citizen in a democracy and that he or she is allowed to be is essential in regard to Dewey's democratic principle of everyone possessing the right and the capacity to be a participating member of a true democracy. The first step in this process is the individual being present during the unhindered and open exchanges between the members of the democracy, because as Dotts (2016) notes, "[democratic education]," the kind that occurs through open exchange of ideas among citizens, "changes the participants involved in interaction" (p. 112). Additionally, Garrison et al. (2016) argue, "At the bottom of this understanding of deep democracy lies the insight that direct faceto-face encounters are powerful experiences" (p. 105). These face-to-face encounters are often necessary for someone to fully consider the needs of someone else. As Dewey notes:

The extension in space of the number of individuals who participate in an interest so that each has to refer his own action to that of others, and to consider the action of others to give point and direction to his own, is equivalent to the breaking down of those barriers of class, race, and national territory which kept men from perceiving the full import of their activity. (MW 9:93) Here Dewey helps to address the necessity of individuals with severe disabilities being present when face-to-face interaction between members of a democracy is occurring. In these instances, those involved, because they are in close proximity to those with disabilities, are made to consider actions suggested will affect all, those with disabilities now included. By being in the room, even those who cannot themselves communicate directly participate by being present in the room.

To tie the forgoing notion of a pluralistic, participatory, communicative democracy together, one should consider another observation Dewey makes:

An undesirable society...is one which internally and externally sets up barriers to free intercourse and communication of experience. A society which makes provision or participation in its good of all its members on equal terms and which secures flexible readjustment of its institutions through interaction of the different forms of associated life is in so far democratic. (MW 9:105)

The key word in this passage is "on equal terms" (MW 9:105), which entails that the interaction of individuals may look different in different contexts, as exemplified by the example of a person with a significant disability participating by solely being present in a democratic space. 


\section{An Aristocracy of Everyone}

When a pluralistic, participatory democracy based in communication amongst participants forms within a school, students can begin to realize their unique potential and develop the skills and attitudes that will allow them to make unique contributions to the society in which they live. Dewey argues that in such a society every citizen has something to offer. For example, a prominent scholar of Dewey, Jim Garrison (2012) states, "The specific needs, desires, and interests, along with moral, artistic, and cognitive development give each individual a unique perspective on existence; hence, the unique ability to make a unique contribution" (p. 354). The notion of unique contribution means that every person has not just an important place in society but possesses something so significant that once society experiences it, the society is unable to live fully without it (Garrison, 2012). It is only possible for a student to find what he or she possesses that is unique when presented with opportunities to explore that in which he or she is uniquely interested.

There is tremendous power in students finding their unique contribution for the reason that when this occurs, the individual-each individual-is able to discover his or her capacity for leadership (Barber 1992); everyone is capable of being a contributing citizen and a leader in some capacity, which I will discuss in the coming paragraphs. Leadership does not just lie in the elite. Leadership is present within every individual, varying only with context. Benjamin Barber speaks to such potential of this in his book An Aristocracy of Everyone. Similar to Dewey, Barber (1992) argues everyone has not just the right, but also the capacity to govern his or her own life and become a citizen. Barber (1992) argues:

Citizens are women and men educated for excellence-by which term I mean the knowledge and competence to govern in common their own lives. The democratic faith is rooted in the belief that all humans are capable of such excellence and have not just the right but the capacity to become citizens. (p. 5)

Barber (1992) is not being idealistic. In fact, he recognizes that, in some instances, students may be unable to master the content, but they can in the very least, be self-governing and master their own lives. Barber (1992) argues, "Not everyone can master string physics or string quartets, but everyone can master the conduct of his or her own life" (p. 13). Therefore, no matter the person, situation, ability, or disability, every person has the capacity to become a contributing citizen and an aristocrat in his or her own right, even if that role of being an aristocrat is being a leader of their own lives.

The notion of unique contribution can be exemplified by re-considering Justin, a student with an intellectual disability to whom I taught vocational skills. In a vocational class there are activities such as sawing or hammering that require objects to be held in a vice. Hammering objects in a vice easily jars the objects out of the vice and onto the floor. Justin was the only person in the class capable of tightening the vice enough that objects could not break free. He was also the only one who could loosen the vice once it was tightened. In regard to being able to operate the vice, Justin was an aristocrat and a leader. 
In the previous example, Justin realized some of his unique potential, found his unique contribution, and this in turn allowed him to find a trait within himself that allowed him to assume a position of leadership. By doing this, he not only helped the others be more productive, but also helped the other students to see that they too had a unique ability that, once discovered, would allow them to assume a similar position in the classroom and perhaps in society. Additionally, physical labor in general contributes to the liberation of the student. Tiboris and Danforth (2016) note, "Dewey seemed to think that this sort of training [practical labor skills] was a crucial element of individual freedom and meaningful activity of life" (p. 653). Therefore, when Justin leaves the classroom, he may be able to reflect back on this situation and think about how since he was successful in a previous environment, then he could be successful in other environments, which could continue to contribute to the renewal process of democratic society.

\section{Democracy For and By the People}

Much of what is called democracy today is only democratic in name. As Parker (1996a) argues, "... it is not so much 'we the people' who govern in these fledgling democracies as it is power elites that govern" (p. 182). Therefore, the argument that everyone has the potential to be a leader is an argument for the disruption of the status quo present in modern politics and in education, too, because it infers that government can and should not only be constructed for the people, but also by the people, which is in line with ideals stated in the founding documents of the United States of America but not yet actualized in the conduct of the American society. In Dewey's time, as in ours, many have, while posturing to support the original intent for a government by the people, are actually in favor of a superior class comprised of the intellectual elite (Westbrook, 1993). During Dewey's time, "Democratic realists" identified a putative problem with democracy and argued that the average citizen was incapable of governing (Westbrook, 2012, p. 293). To react to this claim made by the realists, Dewey "turned to a democratic realist [Walter Lippman] with whom he had the greatest affinity, trading on Lippmann's descriptions and explanations of the plight of democracy while rejecting his solutions to it" (Westbrook, 2012, p. 294). Lippmann's solution was to transition decision making away from ordinary citizens and give authority to the "governing elites" (Westbrook, 2012, p. 299). However, Dewey argues that in instances when the masses are not capable of governing, the solution is to educate the masses, which is reasonable because all are educable. As Westbrook (2012) argues, "The enlightenment of the public,' Dewey said, "took precedence over the enlightenment of government administrators" (p. 310).

The version of democracy to which Lippmann subscribes is likely to occur in a society in which its schools are places where education is created strictly for the students, instead of by the students. If SWDs are placed in situations where "experts," such as administrators, teachers, school psychologists, or central office personnel construct education for them, instead of providing opportunities for the students to co-construct their educational experience, a class of democratic elitists is formed. For example, if students do not have control over their own education, then they are likely not to take control over their life, and then in turn allow themselves to be controlled by others. As Dewey notes, "The man who wears the shoe knows best that it pinches and where it pinches, even if the expert shoemaker is the best judge of how 
the trouble is to be remedied" (LW 2:364). The voice of the student is of utmost importance, as without that voice the group cannot fully know the extent of the problems "to be remedied" (LW 2:364).

Experts have a place in a democracy. When commenting on Dewey's position, Westbrook (2012) argues, "The role of the expert was not as a policy maker but as a technician who would discover and make known to the public and its representatives the facts on which policy making depended" (p. 312). Of course, for sound decision making to take place, members of the public need to understand those facts and what they mean. However, the position of the expert can have differing effects depending on how he or she is first encountered. In the case of SWDs, for instance, before a student qualifies for special education services, experts evaluate him or her. When the meeting occurs to discuss the results, the experts often lead and dominate the discussion. This meeting can send a strong message to the student about her or his role as a student and a citizen. In this type of situation, the student learns from an early age that being a citizen means that he or she is expected, even required, to take a passive role.

Schools that frame the education of students by relying primarily on the insight of "experts" initiates a cycle in which decisions are made by the more knowledgeable, and those decisions are directly experienced by the others deemed "incapable" to make decisions for themselves. Relevant is Garrison's (2012) observation that, "We must cease believing that leadership means government by an elite group of experts. Instead, we must seek government not only for, but also by the people" (p. 373). Along the same lines of sentiment, democratic education is not possible in school systems where education is strictly for the students; all participants must have an opportunity to speak and be heard. Nevertheless, SWDs are often caught in this cycle, ironically when the conversation turns to how to best meet their needs. In these instances, the school often focuses on how it is best to govern the student's life, instead of allowing him or her to govern his or her own life. How can schools educate responsible citizens when the educational system robs them of the responsibilities of citizenship?

\section{Citizenship}

\section{Standard Views of Citizenship}

One of the goals commonly said to be of most importance for American schools is to produce future citizens. As Parker (1996b) notes, "citizenship education is probably the most popular stated mission for schooling in the United States" (p. 104). The question then arises as to exactly how citizenship is defined? Answering this question proves difficult, as many scholars disagree on the precise definition of citizenship. This is because the concept of citizenship, similar to disability, is a contingent societal construct. Johnson (2016) notes, ".... citizenship is a societal construct that functions within the political world of a democracy (at least by Western standards)" (p. 48). Perceptions/conceptions of citizenship depends upon what one has been allowed or disallowed to do in the society in which he or she lives. Therefore, since democratic citizenship is complex and contingent upon previous interactions, situations, events, and environments, attempts to define the concept are ongoing. Henceforth, positions taken in American society regarding the meaning of citizenship fall on one of two sides of a conceptual 
divide. Parker (1996b) says that this division has produced two standard views of citizenship: the traditionalist view and the progressive view. In the view of traditionalists, as it pertains to education, students, it is argued, should be taught about citizenship. In contrast, the progressives demand opportunity for students to practice holding the "office of citizen" in order to help them to become effective as contributing members of society (Parker, 1996b, p. 111). In summation, Parker (1996b) writes, "Traditionalists want more study, progressives want more practice" (p. 112).

In both views, citizenship and the teaching of citizenship, are present in all approaches to education. The traditionalists would argue that students, properly taught, are learning information that they will put to later use when they engage in the act of citizenry. An example of this would be students learning about the responsibilities of civic participation so they know the ways in which they can engage in the act of citizenry when they are of legal age. Progressives, on the other hand, would argue that the school serves as a space for students to engage, then and there in activities where citizenship is being directly practiced. However, neither approaches are in line with Dewey's concept of citizenship, which we will turn our attention to next.

\section{Deweyan Citizenship}

Dewey identifies the notion of "good citizenship", or "civic efficiency" (MW 9:127). He argues that to be a citizen, one must have a position, function, or contribution to society (i.e. a unique contribution). When the concept of citizenship is defined or described in this manner, individuals with disabilities have the potential to be citizens. This is related to the earlier argument of vibrant democracies nurturing students' unique potential so that they can find their unique contribution, which helps them to engage in citizenry. As Dewey notes:

The aim of civic efficiency has at least the merit of protecting us from the notion of a training of mental power at large. It calls attention to the fact that power must be relative to doing something, and to the fact that the things which most need to be done are things which involve one's relationship with others. (MW 9: 127)

Here Dewey ties many of the previous arguments together. For example, he emphasizes that for someone to acquire the position of a leader or an aristocrat, that individual has to be able to do something unique for that society, as in the example of the student with a disability who tightened the vice. This position is not given because of his or her family lineage or the amount of money he or she makes, but is acquired based on the contribution that person makes to the society in which he or she lives. Therefore, here one can see that Dewey views the position of education as cultivating students' unique potential, so they can find their unique contribution, and be not just a citizen, but a good citizen in a creative democracy.

\section{Conclusion}

In this paper I first examined the nature of disability and education, and then provided a conceptualization of the underpinnings of Dewey's pluralistic, participatory, and 
communicative democracy. I then interrogated the concept of citizenship as it pertained to American society and Deweyan democracy. Deweyan democracy should occur everywhere, all the time. Enacting Deweyan democracy has powerful possibilities, especially in the lives of SWDs. Although there are laws and policy initiatives that focus on how to support and protect individuals with disabilities, those efforts do very little if students lack opportunities to explore their educational interests, which, in turn, allows them to realize their unique potential and contribution.

Approaching all students with the mindset that they have the potential to be contributing citizens is controversial, although most people may agree that this is a good idea, conceptually speaking. I believe this is because perhaps we are scared, as a populous, to consider the fact that if all people are allowed to actively participate, that they may not do so the correct way or have the right mindset or answers to societal issues and problems.

However, if we really want to see the franchise of citizenship expanded and extended to everyone, it must start in our schools with our students. In schools across the nation we encourage our students to go forward and succeed, but then when they actually enter life outside of K-12 education, they see that the world is not very equitable, especially for traditionally marginalized groups, like people with disabilities. We encourage the active citizenship of all people verbally, but do we actually mean it? Do we actually embody and enact inclusivity? The evidence suggests that in schools we do not and in society, we still restrict some people from even having the right to vote, suggesting we do not actually seek to include everyone's' voice in the conversation. We have to create students who know they are capable of initiating democratic reform, which is what I am suggesting in this paper.

Every student has the capacity for citizenship and that capacity is not fixed or static, but malleable. Students who engage in democratic education can build their capacity that they can become contributing members of a vibrant democracy. The result is the production of citizens who are capable of leadership. If education maintains the status quo, the field as a whole is contributing to the demise of democracy. Nevertheless, engaging in a true, thriving, democracy has the potential to produce a citizenry where everyone has not just the right to lead, but also the capacity. 


\section{References}

Anastasiou, D., \& Kauffman, J. (2013). The social model of disability: Dichotomy between impairment and disability. Journal of Medicine and Philosophy, 38(4), 441-459. doi:10.1093/jmp/jht026

Baglieri, S., Bejoian, L. M., Broderick, A. A., Connor, D. J., \& Valle, J. (2011). [Re]claiming "inclusive education" toward cohesion in educational reform: Disability studies unravels the myth of the normal child. Teachers College Record, 113(10), 2122-2154.

Ball, S. (2006). Education policy and social class: The selected works of Stephen Ball. New York: Routledge.

Barber, B. (1992). An aristocracy of everyone: The politics of education and the future of America. New York: Ballantine Books.

Barton, L. (1998). Markets, managerialism, and inclusive education. In P. Clough (Ed.) Managing inclusive education (pp. 79-91). London: Paul Chapman Publishing.

Ben-Porath, S. (2012). Defending rights in (special) education. Educational Theory, 62(1), 25-39.

Bérubé, M. (2003). Citizenship and disability. Dissent, 52-57.

Center for Parent Information and Resources. (2017). Categories of disability under IDEA. Retrieved from http://www.parentcenterhub.org/categories/

Citations of the works of Dewey are to the critical edition, The Collected Works of John Dewey, 1882-1953 published by Southern Illinois University Press, Carbondale. Volume and page numbers (or chapter) follow the initials of the series. For instance, MW 9: Chapter 7 refers to Democracy and Education, "The Democratic Conception In Education." Abbreviations for the volumes used are:

MW The Middle Works (1899-1924)

LW The Later Works (1925-1953)

Danforth, S. (2008). John Dewey's contributions to an educational philosophy of intellectual disability. Educational Theory, 58(1), 45-62. doi:10.1111/j.1741-5446.2007.00275.x

Disability Justice. (2016). The right to vote. Retrieved from http://disabilityjustice.org/right-tovote

Dotts, B. W. (2016). Dewey anticipates Habermas's paradigm of communication: The critique of individualism and the basis for moral authority in democracy and education. Education and Culture, 32(1), 111-129Furman, Cara E. "'" Why I Am Not a Painter": Developing an Inclusive Classroom." Education and Culture 31, No. 1 (2015): 61-76. 
EHA (1975). Education for All Handicapped Children Act of 1975 (Public Law 94-142).

ESSA (2015). Every Student Succeeds Act of 2015, Pub. L. No. 114-95 § 114 Stat. 1177 (20152016).

Gabel, S.L. \& Connor, D.J. (2008). Theorizing disability: Implications and applications for social justice in education. In William Ayers, Theresa Quinn, \& David Stovall's (Eds.) The Handbook for Social Justice in Education (pp. 377-389). New York: Routledge.

Garrison, J. (2010). Dewey and eros: Wisdom and desire in the art of teaching. Charlotte: Information Age Publishing.

Garrison, J. (2012). Individuality, equality and creative democracy: The task before us. American Journal of Education, 118(3), 369-379.

Garrison, J., Neubert, S., \& Reich, K. (2016). Democracy and education reconsidered: Dewey after one hundred years. New York and London: Routledge.

Individuals with Disabilities Education Act. (2004). 20 U.S.C. § 1401 et seq.

Johnson, A. P. (2016). How is citizenship represented in theory and research in social education (TRSE)? A content and discourse analysis. (Doctoral dissertation). Retrieved from https://vtechworks-lib-vt-

edu.ezproxy.lib.vt.edu/handle/10919/5534/browse?type=author\&value=Johnson\%2C+Aaron + Paul

Lekan, T. (2009). Disabilities and educational opportunity: A Deweyan approach. Transactions of the Charles S. Peirce Society, 45(2) 214-230. doi:10.2979/tra.2009.45.2.214

Lingard, B. (2008). Pedagogies of indifference. International Journal of Inclusive Education 11(3), 245-266. DOI: 10.1080/13603110701237498.

Martin, J. E., Van Dycke, J. L., Christensen, W. R., Greene, B. A., Gardner, J. E., \& Lovett, D. L. (2006). Increasing student participation in IEP meetings: Establishing the self-directed IEP as an evidenced-based practice. Exceptional Children, 72(3), 299-316.

Mason, L. E. (2016). Cultivating civic habits: A Deweyan analysis of the National Council for the Social Studies position statement on guidelines for social studies teaching and learning. Education and Culture, 32(1), 87-110.

No Child Left Behind (NCLB) Act of 2001, Pub. L. No. 107-110, § 115, Stat. 1425 (2002).

Nespor, J., \& Hicks, D. (2010). Wizards and witches: Parent advocates and contention in special education in the USA. Journal of Education Policy, 25(3), 309-334. 
Nussbaum, M. (2010). The capabilities of people with cognitive disabilities. In Eva Feder Kittay \& Licia Carlson's (Eds.) Cognitive Disability and Its Challenge to Moral Philosophy (pp. 75-95). John Wiley \& Sons.

O'Brien, L.M. (2016). Democracy for all? John Dewey, teacher education, and young children with disabilities. Teacher Education and Practice 29 (3), 476-497.

Parker, W. (1996a). Curriculum for democracy. In R. Sober (Ed.), Democracy, education, and the schools (pp. 182-210). San Francisco: Jossey-Bass Pub.

Parker, W. C. (1996b). "Advanced" ideas about democracy: Toward a pluralist conception of citizenship education. Teachers College Record, 98, 104-125.

Rose, M. (2004). The mind at work. Viking

Shyman, E. (2016). The reinforcement of ableism: Normality, the medical model of disability, and humanism in applied behavior analysis and ASD. Intellectual and Developmental Disabilities, 54(5), 366-376.

Stitzlein, S. M. (2014). Habits of democracy: A Deweyan approach to citizenship education in America today. Education and Culture, 30(2), 61-86.

Tiboris, M., \& Danforth, S. (2016). Learning to occupy yourself: The substantive content of educating for autonomy. Social Theory and Practice, 42(3), 636-654

Westbrook, R. B. (1991). John Dewey and American democracy. Cornell University Press. 